\title{
Serum adiponectin is associated with adverse outcomes of asthma in men but not in women
}

\section{Akshay Sood $^{1}$, Elizabeth Dominic ${ }^{2}$, Clifford Qualls ${ }^{1}$, Michael W. Steffes $^{3}$, Bharat Thyagarajan ${ }^{3}$, Lewis J. Smith ${ }^{4}$, Cora E. Lewis ${ }^{5}$ and David R. Jacobs Jr'}

1 University of New Mexico Health Sciences Center School of Medicine, Albuquerque, NM, USA

${ }^{2}$ University of Rochester, Rochester, NY, USA

${ }^{3}$ University of Minnesota, Minneapolis, MN, USA

${ }^{4}$ The Feinberg School of Medicine, Northwestern University, Chicago, IL, USA

${ }^{5}$ University of Alabama at Birmingham, Birmingham, AL, USA

${ }^{6}$ University of Oslo, Oslo, Norway

\section{Edited by:}

Stelios Loukides, University of Athens Medical School, Greece

Reviewed by:

Adam Antczak, Medical University of Lodz, Poland

Petros Bakakos, Sotira Chest

Hospital, Greece

${ }^{*}$ Correspondence:

Akshay Sood, Division of Pulmonary and Critical Care Medicine,

Department of Medicine, University

of New Mexico Health Sciences

Center School of Medicine, 1

University of New Mexico, MSC 10

5550, ACC 5, Albuquerque, NM

87131, USA.

e-mail: asood@salud.unm.edu
Background: Murine studies suggest a beneficial effect of systemic adiponectin on asthma. Our objective was to determine the association between serum adiponectin concentrations and asthma control/severity outcomes in men and women separately. Methods: Cross-sectional and longitudinal analyses of data from years 10, 15, and 20 examinations of the prospective coronary artery risk development in young adults study in the United States were performed. Asthma was defined by self-reported provider diagnosis at or prior to year 15 examination. Outcomes included presence of active disease, number of respiratory symptoms, and number of asthma medications; as well as longitudinal decline in absolute $\mathrm{FEV}_{1}$. Year 15 serum adiponectin concentration was the predictor variable. Results: In a multivariable analysis of 411 eligible subjects, after adjusting for body mass index and covariates, higher serum adiponectin concentrations were associated with more frequent active disease (including more frequent use of any asthma medication), and greater number of respiratory symptoms and asthma medications among men but not among women with asthma ( $p$ for interactions between sex and adiponectin for all analyses < 0.05). Conclusions: Higher serum adiponectin concentrations may be independently associated with adverse clinical outcomes of asthma in men but not in women. If biological effect is confirmed in future studies, modification of systemic adiponectin concentrations may open up newer ways to treat asthma in men.

Keywords: asthma control and severity, obesity, sex differences, serum adiponectin

\section{INTRODUCTION}

Adipokines, proteins produced by adipose tissue, may regulate systemic inflammation and play a role in asthma (Sood et al., 2006, 2008). Adiponectin is one such adipokine with predominantly anti-inflammatory effects (Kumada et al., 2004; WulsterRadcliffe et al., 2004). Recent studies suggest that adiponectin may also have potential pro-inflammatory effects, as in the synovial tissue of patients with arthritis where it induces interleukin (IL)-6 and matrix metalloproteinase-1 secretion (Ehling et al., 2006).

Although visceral adipocytes are the most important source of adiponectin, serum adiponectin concentrations are reduced in obese subjects. This may be explained by hypoxia-related necrosis of adipocytes in obese subjects, resulting in activation of macrophages (Cinti et al., 2005). These activated macrophages produce tumor necrosis factor-alpha (TNF- $\alpha$ ) and IL-6 which

Abbreviations: BMI, body mass index; CARDIA, coronary artery risk development in young adults; $\mathrm{FEV}_{1}$, forced expiratory volume in one second; $\mathrm{FVC}$, forced vital capacity; HMW, high-molecular weight; HOMA, homeostasis model assessment; IL, interleukin; SAS, Statistical Analysis Software; TNF- $\alpha$, tumor necrosis factor-alpha; YALTA, young adult longitudinal trends in antioxidants. in turn may inhibit the local production of adiponectin in a paracrine fashion (Bruun et al., 2003). Adiponectin and all of its known receptors are expressed in the lung (Miller et al., 2009). Adiponectin is primarily transported from blood into the alveolar lining fluid via the T-cadherin molecule on the endothelium (Hug et al., 2004).

The causative role of low adiponectin in lung disease has been better established in mice than in humans. A study of lean (BALB/cJ) mice of both sexes suggests that exogenous administration of adiponectin attenuates allergen-induced airway hyperreactivity and eosinophilic influx (Figure 1; Shore et al., 2006). Genetically induced adiponectin deficiency in the lungs of normalweight mice results in increased expression of TNF- $\alpha$ in alveolar macrophages (Summer et al., 2008). Although human data remain inconclusive, a cross-sectional study shows that higher serum adiponectin concentrations may be associated with decreased risk for asthma in women (Sood et al., 2008). It is however not known if serum adiponectin affects asthma control/severity outcomes in adults.

The objective of this study was to assess whether serum adiponectin was associated with asthma control/severity outcomes in men and women separately. If systemic adiponectin affects 


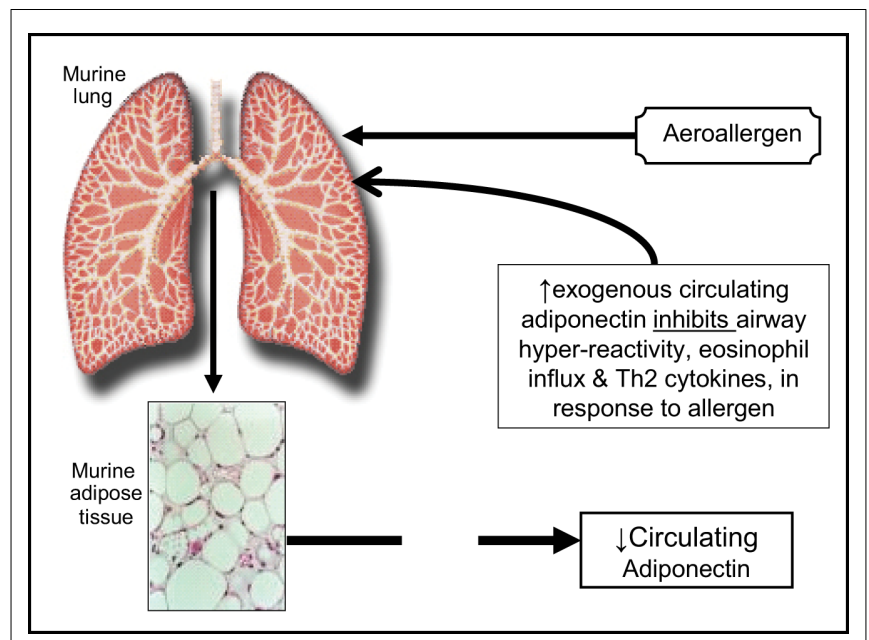

FIGURE 1 |A schematic representation of the suggested role of adiponectin in murine asthma, based on work by Shore et al. (2006).

asthma control/severity outcomes, measures that modify it may lead to newer therapies to treat subjects with asthma.

\section{MATERIALS AND METHODS STUDY DESIGN}

Cross-sectional and longitudinal analyses of data from years 10, 15 , and 20 examinations of the coronary artery risk development in young adults (CARDIA) cohort and its young adult longitudinal trends in antioxidants (YALTA) ancillary study were performed. During 1985-1986, CARDIA randomly recruited 5,115 participants from geographically based populations in Birmingham, AL, USA, Chicago, IL, USA, and Minneapolis, MN, USA by telephone or door-to-door, and from the membership of the Kaiser-Permanente Health Plan in Oakland, CA, USA. About 50\% of those invited participated in the study. At year 0 examination, the study included participants aged $18-30$ years (mean age $24.9 \pm 3.7$ years.) with approximately equal numbers who were black and white, men and women, and high school graduates and dropouts. Follow-up examinations were completed 2, 5, 7, 10,15 , and 20 years later. $3,950,3,672$, and 3,549 persons were respectively examined at years 10,15 , and 20 examinations, constituting $78 \%, 74 \%$, and $72 \%$ respectively of the survivors from the baseline cohort. Detailed methods, instruments, and quality control procedures are described at the CARDIA website (http://www.cardia.dopm.uab.edu/ex_mt.htm) and in other published reports (Hughes et al., 1987; Friedman et al., 1988). While CARDIA is not strictly representative of an identifiable geographic population, it is clearly highly relevant to U.S. populations of young urban and suburban whites and blacks.

\section{INCLUSION AND EXCLUSION CRITERIA}

We included all participants with asthma at CARDIA year 15 examination who also had complete data for serum adiponectin, body mass index (BMI), respiratory symptoms, and covariates, as described below. Asthma was defined as a self-report of a doctor or nurse diagnosis of asthma at any of the years $0,2,5,7,10$, or 15 examinations. Pregnant women, those not fasting for $8 \mathrm{~h}$, or those with missing data at year 15 were excluded.

\section{STUDY MEASUREMENTS}

Self-reported information was obtained by trained interviewers using standardized questionnaires. Menopause was defined by the absence of menstrual periods for the previous 12 months without a specific cause. Pre-menopausal women were defined as experiencing regular menstrual cycles for at least half the time over the previous 12 months, excluding times on birth control pills, pregnant or nursing. Height and weight was measured by trained technicians using standardized equipment with participants wearing light clothing without shoes, and BMI was calculated.

Morning blood samples after at least $8 \mathrm{~h}$ of fasting were collected from seated participants - tourniquet use was limited to 2 min to prevent hemoconcentration. Samples were then centrifuged, aliquoted, and frozen at $-70^{\circ} \mathrm{C}$ within $90 \mathrm{~min}$ of the collection. Total adiponectin was measured in serum as part of the YALTA ancillary study by radioimmunoassay technique at Linco Research, Inc. (St. Charles, MO, USA) using a polyclonal antibody raised in a rabbit and purified recombinant adiponectin standards with an effective range of $0.2-40 \mathrm{mg} / \mathrm{L}$ (Cnop et al., 2003). Correlation between serum adiponectin concentrations measured in blinded repeat samples from 407 subjects was 0.91 and the inter-assay coefficient of variation for our laboratory was $8.8 \%$.

Prebronchodilator spirometry was performed at year 10 using a Collins Survey 8-liter water sealed spirometer and an Eagle II Microprocessor (Warren E. Collins, Inc., Braintree, MA, USA). At year 20, a dry rolling-seal OMI spirometer (Viasys Corp, Loma Linda, CA, USA) was used. No spirometry data were collected at year 15 and therefore year 20 spirometry data were used in lieu of year 15 data. A comparability study performed on 25 volunteers demonstrated excellent consistency without systematic differences between the old and new machines; the average difference being $6 \mathrm{~mL}$ for forced vital capacity (FVC) and $21 \mathrm{~mL}$ for $\mathrm{FEV}_{1}$. Standard spirometry quality control and testing procedures were followed at all examinations (American Thoracic Society, 1995; Miller et al., 2005).

\section{OUTCOME AND PREDICTOR VARIABLES}

Asthma control and severity is a complex outcome that is difficult to define well (Reddel et al., 2009). Existing clinical scales focus on three domains - respiratory symptoms, asthma medication use and pulmonary function. However, these scales are not easily adapted to population-based research where access to detailed clinical information is usually not available (Ungar et al., 2002; Reddel et al., 2009). Surrogate outcome variables for each of the three domains were therefore used. These included clinical outcomes such as presence of active disease as defined below (and its component, namely the use of any asthma medication); number of respiratory symptoms; and number of asthma medications used at year 15 examination; as well as physiological outcomes such as longitudinal decline in absolute prebronchodilator $\mathrm{FEV}_{1}$ between years 10 and 20 . The primary predictor variable for all analyzes was year 15 serum adiponectin concentration. The time axis for measurement of various predictor and outcome variables is depicted in Figure 2. 


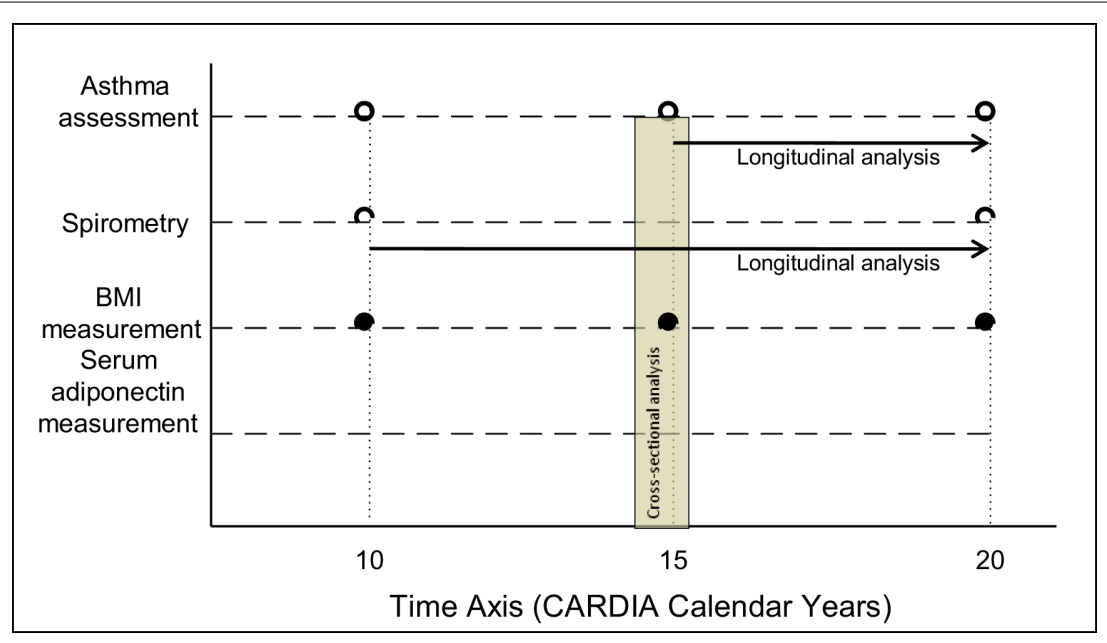

FIGURE 2 | Selected time axis for measurement of various outcome and predictor variables in the CARDIA study.

Active disease, a composite variable involving asthma symptoms and medications, was defined as a subject report of either taking a validated asthma medication at the time of examination or of symptoms of asthma during the 1-year period prior to the examination. Further, use of any asthma medication and number of asthma medications used are correlated with asthma severity in population-based research (Ungar et al., 2002). For our analyses, the need for asthma medication was equated with report of taking the medication under a prescription. Asthma medications studied included short and long-acting inhaled and oral $\beta 2$ agonists, inhaled and oral corticosteroids, leukotriene receptor antagonists, theophylline, anticholinergic inhalers, and immunotherapy - the daily dose of inhaled corticosteroid was however not obtained. Validation of medication use was performed by direct examination of medication by trained study personnel.

The number of respiratory symptoms was obtained from coding the following seven questions with binary responses: (1) Does your chest ever sound wheezy or whistling when you have a cold? (2) Does your chest sound wheezy or whistling occasionally apart from a cold? (3) Have you ever had an attack of wheezing that made you feel short of breath? (4) Have you had two or more episodes of attacks of wheezing that made you feel short of breath? (5) Are you troubled by shortness of breath when hurrying on the level or walking up a slight hill? (6) When walking on level ground, do you have to walk slower than people your age because of breathlessness? and (7) Do you ever have to stop for breath when walking at your own pace on level ground?

In addition to the above clinical measures, longitudinal change in absolute $\mathrm{FEV}_{1}$ between years 10 and 20 examinations was also analyzed. This outcome is associated with changes in most other asthma outcome measures and may be a marker for airway remodeling (Covar et al., 2004; Reddel et al., 2009).

\section{STATISTICAL METHODS}

Serum adiponectin concentration was studied as a continuous variable after logarithmic transformation that yielded normal distribution of adiponectin with effects on categorical and continuous outcomes being approximately linear. BMI was also used as a continuous variable. Odds ratios from logistic regression were used for categorical outcomes (i.e., presence of active disease and use of any asthma medication). Slope estimates from Poisson regression were used for count outcomes (number of respiratory symptoms and number of asthma medications used) using Statistical Analysis Software (SAS) proc genmod and rate ratios corresponding to the slope parameters were calculated. The distribution of these outcomes was approximately Poisson distributed. Estimates of longitudinal change in lung function were further obtained from general linear model using SAS proc glm. The change in lung function was approximately normally distributed. Given the possible difference in adiponectin effect between men and women (Sood et al., 2008), we performed formal tests for sex interaction in the whole group and further examined subgroups defined by sex.

Covariates included in all models as a block were self-reported smoking status, race (blacks vs. whites), and age - all measured at year 15 examination. Smoking was treated as a categorical variable, including current, former, and never smokers. Diabetes mellitus, insulin resistance [defined by the homeostasis model assessment (HOMA)], and physical activity level (based upon the questionnaire-assessed physical activity history score) were not included since they were not noted to contribute significantly to these models, using stepwise regression. SAS (9.1.3, Cary, NC, USA) was used. A two-sided $p$ value of $<0.05$ was considered statistically significant.

All subjects gave informed consent for their participation in the study. This study was approved by the Institutional Review Boards at University of New Mexico, Albuquerque, NM, USA and at each of the CARDIA study sites.

\section{RESULTS}

DEMOGRAPHIC CHARACTERISTICS

Of the 3,672 subjects in the CARDIA cohort at year 15 examination, 468 subjects had asthma, of which 411 subjects ( 258 women and 153 men) had complete additional data (see Figure 3). Of 


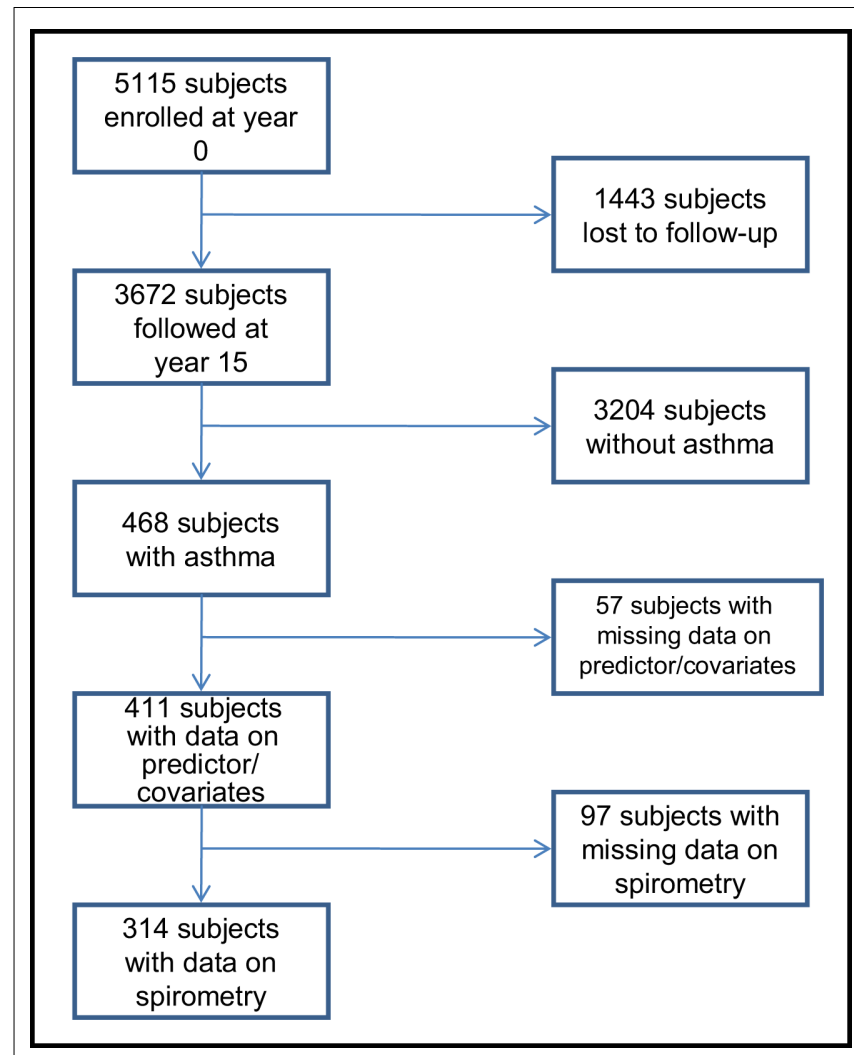

FIGURE 3 | Flowchart of subject inclusion.

these 411 eligible subjects, 314 subjects (201 women and 113 men) additionally had complete spirometry data and 248 (171 women and $77 \mathrm{men}$ ) had active disease. Further, a review of validated medication use showed that $66.1 \%$ of those with active disease were using at least one asthma medication (mean number and SD of asthma medications used were $1.1 \pm 1.1$ ) and $27.8 \%$ were using inhaled corticosteroids. Therefore, most subjects in this study were presumed to have asthma of "intermittent" or "mild persistent" severity (National Heart Lung and Blood Institute, 2007a). As reported previously (Hankinson et al., 1999; Sood et al., 2008; Nagel et al., 2009), women with asthma had greater $\mathrm{BMI}$, serum adiponectin concentrations, and $\mathrm{FEV}_{1} / \mathrm{FVC}$ percent than men with asthma (Table 1).

\section{SERUM ADIPONECTIN IS ASSOCIATED WITH ADVERSE CLINICAL OUTCOMES OF ASTHMA IN MEN BUT NOT IN WOMEN}

Among men with asthma, higher serum adiponectin concentrations were associated with greater odds of having active disease, using any asthma medication, having more respiratory symptoms, and using more asthma medications, after adjusting for block covariates and BMI (Table 2). Interactions between sex and serum adiponectin were significant for each of the above outcomes in the multivariable analyses, confirming that these associations differed between men and women with asthma.

Among women with asthma, higher serum adiponectin concentrations were thus associated with lower odds of having active disease, although this association did not reach significance in the
Table 1 | Distribution of selected demographic characteristics among women and men with asthma.

\begin{tabular}{|c|c|c|}
\hline Characteristics & Women $(n=258)$ & Men $(n=153)$ \\
\hline Age (in years) & $40.3 \pm 3.6$ & $40.0 \pm 3.6$ \\
\hline Race (\% whites) & 46.1 & 54.3 \\
\hline $\begin{array}{l}\text { Low annual household income } \\
(\%,<\$ 25,000)\end{array}$ & 20.7 & 14.4 \\
\hline $\begin{array}{l}\text { Low educational status (\%, } \\
\leq \text { high school graduate) }\end{array}$ & 23.0 & 22.7 \\
\hline $\begin{array}{l}\text { Lack of coverage for medical } \\
\text { care }(\%)^{\dagger}\end{array}$ & 11.3 & 19.7 \\
\hline $\begin{array}{l}\text { Difficult access to medical care } \\
(\%)\end{array}$ & 12.1 & 11.3 \\
\hline Current smokers $(\%)^{\dagger}$ & 19.4 & 22.2 \\
\hline $\begin{array}{l}\text { History of diabetes mellitus } \\
(\%)^{\dagger}\end{array}$ & 10.3 & 4.0 \\
\hline Insulin resistance (HOMA units) & $2.8(2.6,3.1)$ & $2.6(2.4,2.9)$ \\
\hline $\begin{array}{l}\text { Physical activity (in exercise } \\
\text { units) }^{\dagger}\end{array}$ & $\begin{array}{l}171.1 \\
(149.6,195.8)\end{array}$ & $\begin{array}{l}298.5 \\
(248.9,358.0)\end{array}$ \\
\hline Body mass index (in $\left.\mathrm{kg} / \mathrm{m}^{2}\right)^{\dagger}$ & $31.7 \pm 9.0$ & $28.5 \pm 5.8$ \\
\hline $\begin{array}{l}\text { Serum adiponectin } \\
\text { concentration }(\mathrm{mg} / \mathrm{L})^{\dagger}\end{array}$ & $10.0(9.3,10.8)$ & $7.3(6.7,8.0)$ \\
\hline $\begin{array}{l}\text { Number of respiratory } \\
\text { symptoms }{ }^{\dagger}\end{array}$ & $3.6 \pm 1.8$ & $3.0 \pm 1.8$ \\
\hline Active asthma $(\%)^{\dagger}$ & 66.3 & 50.3 \\
\hline $\begin{array}{l}\text { Number of respiratory } \\
\text { symptoms* }\end{array}$ & $4.1 \pm 1.7$ & $3.9 \pm 1.6$ \\
\hline Asthma medication use $(\%)^{*}$ & 63.2 & 72.7 \\
\hline Inhaled corticosteroid use $(\%)^{*}$ & 25.2 & 33.8 \\
\hline $\begin{array}{l}\text { Number of asthma medications } \\
\text { used* }\end{array}$ & $1.0 \pm 1.0$ & $1.3 \pm 1.3$ \\
\hline $\begin{array}{l}\text { Percent } \mathrm{FEV}_{1} / \mathrm{FVC} \text { ratio at year } \\
10^{\dagger}\end{array}$ & $78.2 \pm 7.2$ & $73.3 \pm 9.4$ \\
\hline $\begin{array}{l}\text { Percent predicted } \mathrm{FEV}_{1} \text { at year } \\
10^{\dagger}\end{array}$ & $94.9 \pm 14.9$ & $88.5 \pm 15.6$ \\
\hline $\begin{array}{l}\text { Percent } F E V_{1} / F V C \text { ratio at year } \\
20^{\dagger}\end{array}$ & $77.2 \pm 7.3$ & $72.4 \pm 10.0$ \\
\hline $\begin{array}{l}\text { Percent predicted } \mathrm{FEV}_{1} \text { at year } \\
20\end{array}$ & $89.3 \pm 15.5$ & $86.0 \pm 17.3$ \\
\hline $\begin{array}{l}\text { Ten-year (years } 20-10 \text { ) change } \\
\text { in absolute } \mathrm{FEV}_{1}(\mathrm{~mL})\end{array}$ & $341 \pm 273$ & $321 \pm 296$ \\
\hline
\end{tabular}

All data is measured at CARDIA year 15 examination unless otherwise indicated. Data is presented as mean $\pm S D$. Geometrical mean is presented with $95 \% \mathrm{Cl}$ in parentheses. Lung function data is presented from a subset of 314 participants (201 women and 113 men) with asthma. Race-specific equations from the Third National Health and Nutrition Examination Survey were used to obtain predicted values for FEV $1 .{ }^{+}$Comparisons between men and women with asthma significant at $p$ value $<0.05$. *Analysis was performed in the subgroup of 248 participants (171 women and $77 \mathrm{men}$ ) with active asthma. HOMA, homeostasis model assessment; FEV , forced expiratory volume in one second; FVC, forced vital capacity.

multivariable analysis. Although women showed no associations between serum adiponectin and other measures of clinical outcomes, these associations were different from men with asthma. 


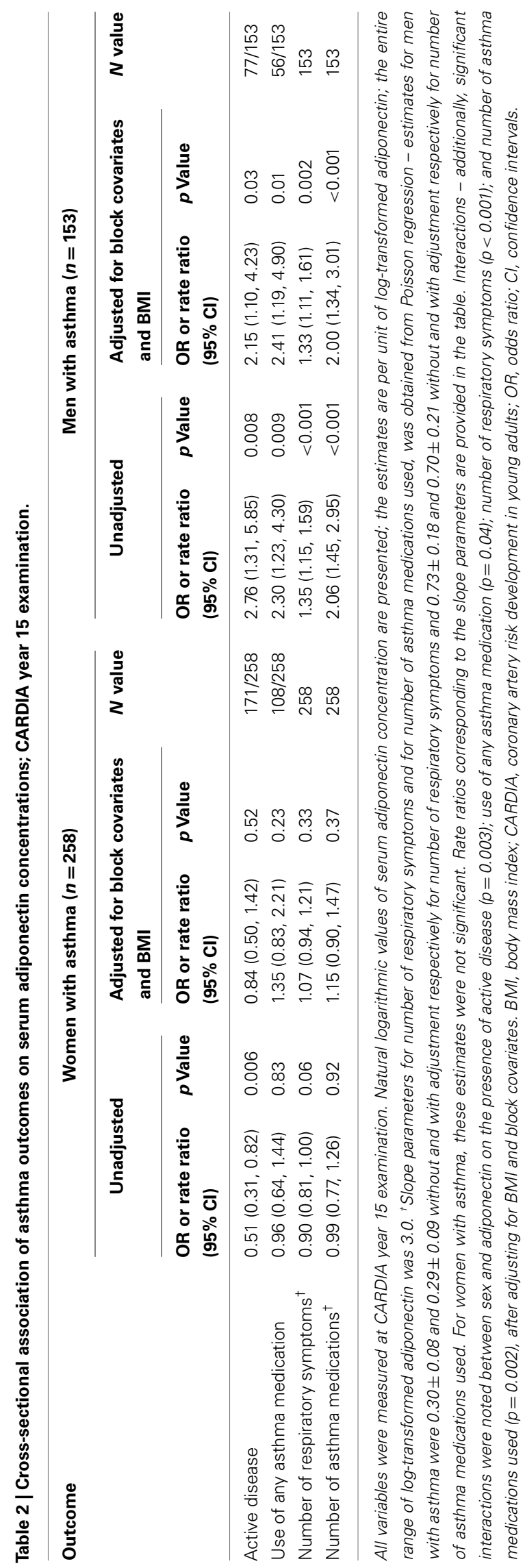


Additionally, among pre-menopausal women with asthma, similar effects were seen as among all women with asthma.

\section{DIRECTION OF ASSOCIATION IS THAT ADIPONECTIN AFFECTS ASTHMA IN MEN (LONGITUDINAL ANALYSES)}

Additional longitudinal analyses were performed to evaluate the direction of the association between asthma outcomes measures at year 20 and 15 serum adiponectin concentrations. These results (in Table 3) show the same direction of association as those described in Table 2. Further, we did not find either prevalent asthma or inhaled corticosteroid use at year 10 examination to predict serum adiponectin concentration at year 15 . These analyses suggest that adiponectin affects asthma outcomes in men rather than the reverse direction.

\section{BMI IS ASSOCIATED WITH ADVERSE CLINICAL OUTCOMES OF ASTHMA IN WOMEN BUT NOT IN MEN}

Among men with asthma, BMI was not associated with any clinical outcomes of asthma (Table 4). In contrast, higher BMI was associated with greater odds of having active disease, using any asthma medication, having more respiratory symptoms, and using more asthma medications among women with asthma, after adjusting for block covariates and serum adiponectin concentrations. Interactions between sex and BMI were significant for presence of active disease, number of respiratory symptoms and number of asthma medications used in the multivariable analyses, suggesting that these associations were different between men and women. Additionally, among pre-menopausal women with asthma, similar effects were seen as among all women with asthma.

\section{NEITHER SERUM ADIPONECTIN NOR BMI IS ASSOCIATED WITH CHANGE IN FEV 1 AMONG PARTICIPANTS WITH ASTHMA}

Neither serum adiponectin concentrations nor BMI at year 15 were associated with change in absolute $\mathrm{FEV}_{1}$ between years 10 and 20 in men or women with asthma (Tables 3 and 4). Additional adjustment for height and height ${ }^{2}$ in these models did not change the results. The effects of year $10 \mathrm{BMI}$ and of change in BMI between years 10 and 15 on the change in absolute $\mathrm{FEV}_{1}$ were also separately explored, and results were similar to those described above using year 15 BMI levels. Among pre-menopausal women with asthma, similar effects were seen as among all women.

\section{ALTERNATIVE ANALYTIC STRATEGIES}

Additional adjustment for atopic status (defined by the presence of hay fever) at baseline (CARDIA year 0 ) examination did not affect the results. Data on atopic status at year 15 examination were not collected. The analysis was also rerun among those participants at year 15 examination who ever noted wheezing, as opposed to asthma as defined previously ( $n=930 ; 386 \mathrm{men}$; and 544 women); the results were unchanged. The analysis was then rerun for subjects with active asthma only ( $n=77$ men and 171 women); the direction of associations was similar to that described in Tables 2 and 4 but many of the associations lost statistical significance due to reduced sample size. We evaluated the associations of change in absolute $\mathrm{FEV}_{1}$ on serum adiponectin in Table 2 and on BMI in Table 4 after adding both height and height ${ }^{2}$ in the adjusted models and found similar results as above. Similarly, adding inhaled corticosteroid use to the adjusted models did not affect the results.
Finally, the use of waist circumference instead of BMI in the adjusted models did not affect the change in $\mathrm{FEV}_{1}$ results.

\section{DISCUSSION}

In this study, higher serum adiponectin concentrations may be associated with adverse clinical outcomes of disease only among men with asthma. Additionally, BMI may be associated with adverse clinical outcomes of disease only among women with asthma. The association of serum adiponectin with adverse clinical outcomes of asthma in men is interestingly in contrast to our previously reported findings that serum adiponectin may be associated with decreased prevalence of asthma in women (Sood et al., 2008) as well as to murine studies showing attenuation of airway hyperreactivity and eosinophilic influx by adiponectin (Shore et al., 2006). Taking these studies together, our data suggest that the mechanisms of the associations between obesity, adipokines and asthma are complex and are different between men and women. Further, the findings from the mouse model (Shore et al., 2006) may not be easily translated to humans and particularly men.

We confirm our cross-sectional results in Table 2 by performing additional longitudinal analyses in Table 3 that suggest that greater serum adiponectin concentrations may worsen the clinical outcomes of asthma among men and not vice versa. Further confirmation of the temporal sequence was provided by our previously published study that showed that serum adiponectin concentrations were unaffected by inhaled allergen-induced bronchoprovocation in sensitized subjects with asthma (Sood et al., 2009). Further, we did not find either prevalent asthma or inhaled corticosteroid use at year 10 examination in the CARDIA study to predict serum adiponectin concentration at year 15. This suggests that there are no acute or chronic effects of asthma on serum adiponectin concentrations.

Although counter-intuitive, there are various explanations for the possibly adverse effects of serum adiponectin on clinical asthma outcomes in men. There may be a gender-related difference in asthma phenotype that may explain our findings. There may be a threshold above which serum adiponectin may have no effect on asthma - concentrations in men usually fall below that threshold and thus demonstrate an association whereas those in women usually fall above that threshold and demonstrate no association. Of note, our graphic exploration of data did not however suggest such a non-linear association. Further, systemic testosterone may either blunt the anti-inflammatory airway effect of adiponectin or augment its little-known pro-inflammatory effect. The highmolecular weight (HMW) isoform of systemic adiponectin may be the beneficial form for asthma, which is disproportionately reduced in men as compared to women (Page et al., 2005; Andersen et al., 2007). Finally, lungs in men may have receptormediated resistance to the beneficial effects of adiponectin. It should be noted that the sex-related differences in adiponectin's anti-inflammatory function have been similarly described in previous studies of markers of cardiovascular disease (Lawlor et al., 2005; Onat et al., 2008). If it is true that greater serum adiponectin concentrations worsen clinical control/severity of disease among men with asthma, pharmacologic measures to "blindly" increase concentrations of all isoforms of serum adiponectin in future clinical trials may in fact be harmful among men with asthma. 


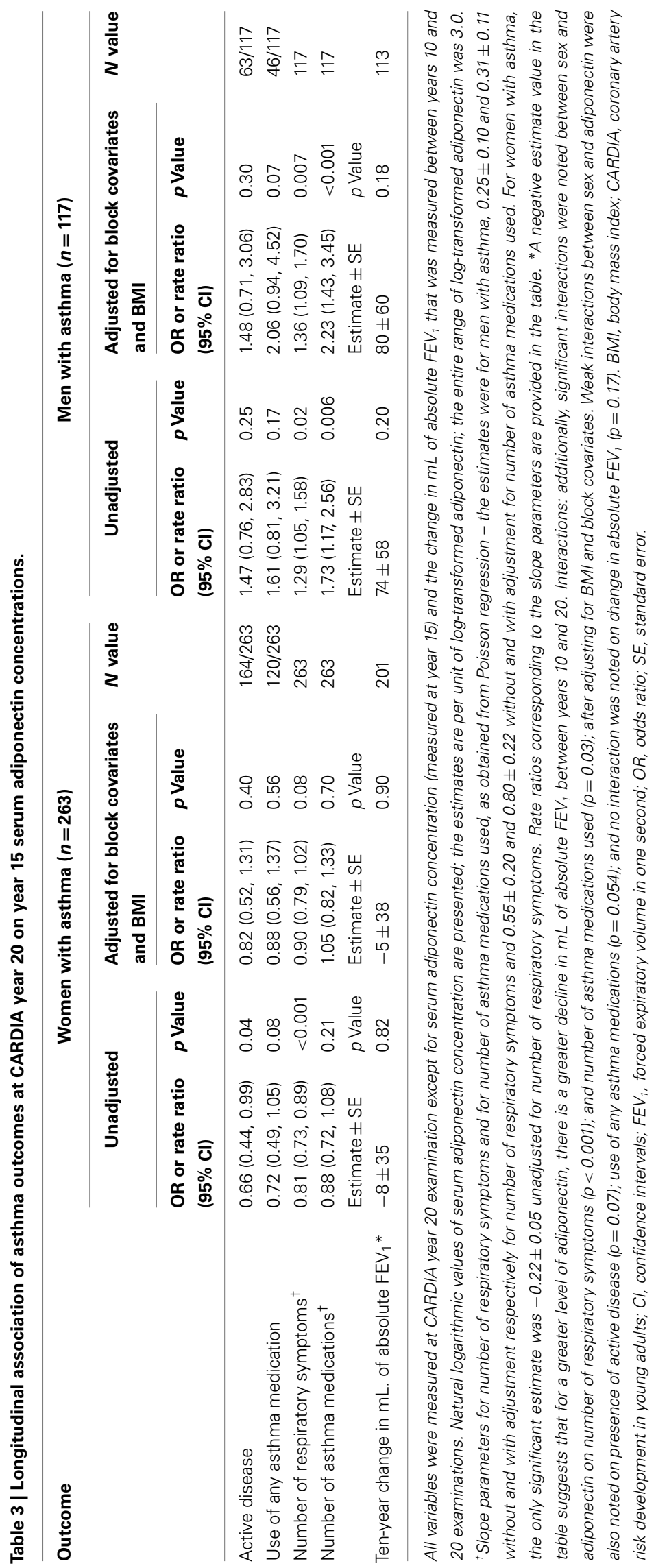




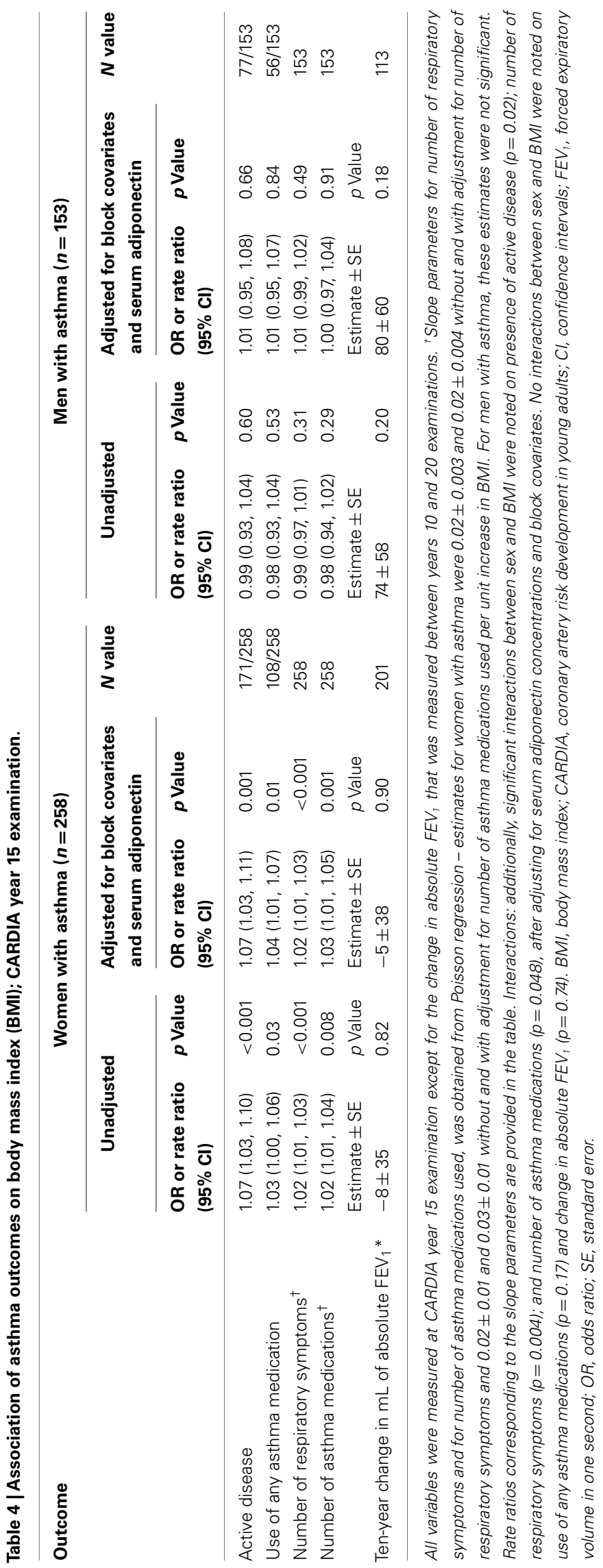


Interestingly, a recent study of 14-year old boys by Kattan et al. (2010) showed that greater systemic adiponectin was associated with better asthma control, opposite of what we describe in middle-aged men. It is possible that these conflicting results may be explained by testosterone-related change in adiponectin isoform distribution (toward a lower proportion of HMW isoform) that occurs in men (Page et al., 2005; Andersen et al., 2007). Recent studies suggest that the HMW isoform is the most biologically active form of adiponectin in regulating insulin resistance (Hara et al., 2006). Whether the same is true for asthma is not known but the airway preponderance of the HMW isoform in mice suggests that may be the case (Zhu et al., 2010). The study by Kattan et al. (2010) also differed from ours in its use of clinic-based recruitment; exclusion of mild asthma; and lack of multivariable analyses and of longitudinal pulmonary function data.

A New Zealand-based birth cohort study (Sutherland et al., 2009b) showed that serum adiponectin concentrations were negatively correlated with fractional exhaled nitric oxide levels among men $(-0.16 ; 95 \% \mathrm{CI}-0.29,-0.04 ; p=0.009)$ in an adjusted analysis. Of note, these data included both men with and without asthma diagnosis. Our study, on the other hand, was restricted to those with asthma diagnosis alone and did not measure exhaled nitric oxide levels. Further, Sutherland's unadjusted analysis showed that high serum adiponectin concentrations were associated with greater, not lower odds for prevalent reversible airflow obstruction among men. The latter data suggest a proinflammatory effect of adiponectin in men and contradict the exhaled nitric oxide data which suggest an anti-inflammatory effect of adiponectin. Finally, unlike our study, Sutherland et al. did not report significant sex-specific interactions for asthma-related outcomes.

Additionally, since adiponectin inhibits proliferation of vascular smooth muscle cells (Ouchi et al., 1999; Kondo et al., 2002; Okamoto et al., 2002), it has been hypothesized that adiponectin may inhibit airway smooth muscle proliferation (Shore, 2006), thus improving airway remodeling in chronic asthma. Our study however did not find any significant effect of serum adiponectin on time-dependent decrease in $\mathrm{FEV}_{1}$. We therefore conclude that it is unlikely that systemic adiponectin may improve in vivo airway remodeling in human asthma. This is consistent with recent reports that adiponectin did not affect airway smooth muscle proliferation in mice or in vitro human experiments (Shin et al., 2008; Medoff et al., 2009).

Prior studies of the association between obesity and asthma outcomes have yielded conflicting results (Tantisira et al., 2003; The Enfumosa Study Group, 2003; Wenzel and Busse, 2007; Mosen et al., 2008; Taylor et al., 2008; Vortmann and Eisner, 2008; Sutherland et al., 2009a). Our study demonstrates that obesity is associated with adverse clinical outcomes of asthma but additionally report these findings only in women. We further show that serum adiponectin does not explain away the effect of obesity on clinical outcomes of asthma in women, suggesting that the effect of obesity may be mediated via multiple pathways including both mechanical and inflammatory.

The strengths of our study include its sex-specific stratified analysis, well-defined study population set within a cohort structure, and its clinical translational character, based on the recently published data on the role of systemic adiponectin in mouse and human asthma (Shore, 2006; Shore et al., 2006; Sood et al., 2008; Nagel et al., 2009). Further, the results from our cross-sectional analyses are supported by our longitudinal analyses. Another unique feature of our study is its community-based, rather than clinic-based recruitment.

The study however, has several limitations. One significant limitation is the use of self-report of provider-diagnosed asthma. However, self-report is the standard definition used in epidemiological studies, despite the misclassification bias relative to the "gold standard" of airway hyperresponsiveness (Aaron et al., 2008). Although asthma misclassification has not been studied with respect to adiponectin, this misclassification is non-differential between obese and non-obese subjects (Appleton et al., 2006; Aaron et al., 2008; Lang et al., 2009). With non-differential misclassification errors, the bias is typically in a predictable direction (i.e., toward lack of association) and unlikely to produce a spurious effect. Additionally, self-report may miss subjects with mild asthma severity. However, this is unlikely, given that most subjects in our community-based study were of mild intermittent severity, as suggested by their relatively low rates of inhaled corticosteroid use shown in Table $\mathbf{1}$ (National Heart Lung and Blood Institute, 2007a). This distribution is however consistent with another community-based study where intermittent disease was also the most prevalent asthma type (Fuhlbrigge et al., 2002). Not surprisingly, the proportion of subjects with moderate or severe asthma in our study was smaller than most clinic-based studies - this may affect the generalizability of our findings. We cannot entirely rule out the possibility of the misdiagnosis of chronic obstructive pulmonary disease (COPD) subjects as asthma in our study. However, this possibility is less likely given the relatively young age of subjects ( $40.2 \pm 3.6$ years); high proportion of never smokers $(59.3 \%)$; and rare use of anti-muscarinic inhaler drugs (two subjects using ipratropium and another four using ipratropiumalbuterol combination) at CARDIA year 15 examination as well as the high levels of year 10 mean prebronchodilator $\mathrm{FEV}_{1} / \mathrm{FVC}$ ratio $(76.8 \pm 8.1 \%)$. Further, we do adjust for smoking behavior, the most important risk factor for COPD, without affecting our results. Further, current definitions of asthma control/severity are less than ideal, particularly for population research (Ungar et al., 2002; Reddel et al., 2009). Although it is reasonable to study medication use as a measure of asthma control/severity (Cockcroft and Swystun, 1996), our assumption that the need for asthma medication can be equated with report of taking the medication may not be entirely true. The lowest dose of maintenance inhaled corticosteroids required after asthma control is achieved, a key measure in assessing clinical disease severity among treated patients (National Heart Lung and Blood Institute, 2007a,b), was not available in this population study. Additionally, data assessing symptomatic asthma control using standardized asthma questionnaires were not collected in this population study. On the other hand, we analyzed a number of respiratory symptoms that may be relevant for several cardiopulmonary conditions including asthma and systemic conditions including obesity. It should nevertheless be pointed out that there were no cases with clinical atherosclerotic cardiovascular disease among the 411 subjects studied at year 15 and that we adjusted for obesity in our models. Longitudinal 
analysis of the effect of year 15 serum adiponectin on subsequent change in lung function requires the baseline lung function to be assessed at year 15. Unfortunately, spirometry was not performed at CARDIA year 15 examination and therefore spirometry at year 10 was instead used as baseline (Figure 2).

Selection bias may occur if subjects with adiponectin measurements were not representative of the total asthma population. However, we found that subjects with asthma with or without adiponectin measurements did not differ with respect to either obesity or asthma outcomes measures (data not shown). Further, data on atopy were not collected at CARDIA year 15 examination. However, adjustment for self-reported atopic status at year 0 examination did not affect the results. This study did not measure the serum concentrations of various isoforms of adiponectin, other adipokines, or reproductive hormones. It is possible that the various isoforms have varying in vivo activity for asthma. It is also not clear whether there is a correlation between serum and airway concentrations of total adiponectin and its isoforms. Further, a single assessment of a biomarker may be susceptible to short-term variation and may not reflect long-term exposure. However, studies suggest that serum concentrations of adiponectin are stable (Pischon et al., 2003; Lukanova et al., 2006; Kaplan et al., 2007) and therefore, it is a good candidate for long-term risk assessment. Our data in Table 2 are cross-sectional which limits our ability

\section{REFERENCES}

Aaron, S. D., Vandemheen, K. L., Boulet, L. P., Mcivor, R. A., Fitzgerald, J. M., Hernandez, P., Lemiere, C., Sharma, S., Field, S. K., Alvarez, G. G., Dales, R. E., Doucette, S., and Fergusson, D. (2008). Over diagnosis of asthma in obese and non-obese adults. CMAJ 179, 1121-1131.

American Thoracic Society. (1995). Standardization of spirometry, 1994 update. Am. J. Respir. Crit. Care Med. 152, 1107-1136.

Andersen, K. K., Frystyk, J., Wolthers, O. D., Heuck, C., and Flyvbjerg, A. (2007). Gender differences of oligomers and total adiponectin during puberty: a cross-sectional study of 859 Danish school children. J. Clin. Endocrinol. Metab. 92, 1857-1862.

Appleton, S. L., Adams, R. J., Wilson, D. H., Taylor, A. W., and Ruffin, R. E. (2006). Central obesity is associated with non-atopic but not atopic asthma in a representative population sample. J. Allergy Clin. Immunol. 118, 1284-1291.

Bruun, J. M., Lihn, A. S., Verdich, C., Pedersen, S. B., Toubro, S., Astrup, A., and Richelsen, B. (2003). Regulation of adiponectin by adipose tissue-derived cytokines: in vivo and in vitro investigations in humans. Am. J. Physiol. Endocrinol. Metab. 285, E527-E533.
Cinti, S., Mitchell, G., Barbatelli, G., Murano, I., Ceresi, E., Faloia, E. Wang, S., Fortier, M., Greenberg, A. S., and Obin, M. S. (2005). Adipocyte death defines macrophage localization and function in adipose tissue of obese mice and humans. J. Lipid Res. 46, 2347-2355.

Cnop, M., Havel, P. J., Utzschneider, K. M., Carr, D. B., Sinha, M. K., Boyko, E. J., Retzlaff, B. M., Knopp, R. H., Brunzell, J. D., and Kahn, S. E. (2003). Relationship of adiponectin to body fat distribution, insulin sensitivity and plasma lipoproteins: evidence for independent roles of age and sex. Diabetologie 46, 459-469.

Cockcroft, D. W., and Swystun, V. A. (1996). Asthma control versus asthma severity. J. Allergy Clin. Immunol. 98, 1016-1018.

Covar, R. A., Spahn, J. D., Murphy, J. R., and Szefler, S. J. (2004). Progression of asthma measured by lung function in the childhood asthma management program. Am. J. Respir. Crit. Care Med. 170, 234-241.

Ehling, A., Schaffler, A., Herfarth, H., Tarner, I. H., Anders, S., Distler, O., Paul, G., Distler, J., Gay, S., Scholmerich, J., Neumann, E., potential of adiponectin in driving arthritis. J. Immunol. 176, 4468-4478.

Friedman, G. D., Cutter, G. R., Donahue, R. P., Hughes, G. H., Hulley, S. B., and Muller-Ladner, U. (2006). The

to infer causality. However, the cross-sectional findings are supported by longitudinal data in Table 3 that allow for inference of the direction of association. It is still however premature to conclude a causal association between serum adiponectin and asthma control/severity.

In summary, our study of predominantly mild asthma from a community-based middle-aged population shows that systemic adiponectin concentrations may have opposing associations with clinical control/severity outcomes of asthma between men and women. Among men with asthma, higher systemic adiponectin concentrations may adversely affect clinical outcomes of disease. Future studies involving the modification of systemic adiponectin concentrations may open up newer ways to treat asthma in men.

\section{ACKNOWLEDGMENTS}

The authors thank Ravi Kalhan, M. D., Northwestern University, Chicago, IL, USA and Mark Schuyler, M. D., University of New Mexico, Albuquerque, NM, USA for their careful critiques of the manuscript. Declaration of all sources of funding: This study is supported by CARDIA contracts N01-HC-48047-50 and N01HC-95095 and an ancillary study R01 HL 53560. Dr. Sood is supported by 1K23HL094531-01 and DHHS/NIH/NCRR/GCRC Grant \# 5M01 RR00997. None of the sponsors played any role in study design, execution, or analysis or preparation of manuscript.

Jacobs, D. R. Jr., Liu, K., and Savage, P. J. (1988). CARDIA: study design, recruitment, and some characteristics of the examined subjects. J. Clin. Epidemiol. 41, 1105-1116.

Fuhlbrigge, A. L., Adams, R. J., Guilbert, T. W., Grant, E., Lozano, P., Janson, S. L., Martinez, F., Weiss, K. B., and Weiss, S. T. (2002). The burden of asthma in the United States: level and distribution are dependent on interpretation of the national asthma education and prevention program guidelines. Am. J. Respir. Crit. Care Med. 166, 1044-1049.

Hankinson, J. L., Odencrantz, J. R., and Fedan, K. B. (1999). Spirometric reference values from a sample of the general U.S. population. Am. J. Respir. Crit. Care Med. 159, 179-187.

Hara, K., Horikoshi, M., Yamauchi, T., Yago, H., Miyazaki, O., Ebinuma, H., Imai, Y., Nagai, R., and Kadowaki, T. (2006). Measurement of the high-molecular weight form of adiponectin in plasma is useful for the prediction of insulin resistance and metabolic syndrome. Diabetes Care 29, 1357-1362.

Hug, C., Wang, J., Ahmad, N. S., Bogan, J. S., Tsao, T. S., and Lodish, H. F. (2004). T-cadherin is a receptor for hexameric and high-molecular-weight forms of Acrp30/adiponectin. Proc. Natl. Acad. Sci. U.S.A. 101, 10308-10313.
Hughes, G. H., Cutter, G., Donahue, R., Friedman, G. D., Hulley, S., Hunkeler, E., Jacobs, D. R. Jr., Liu, K., Orden, S., Pirie, P., Tucker, B., and Wagenknecht, L. E. (1987). Recruitment in the coronary artery disease risk development in young adults (cardia) study. Control. Clin. Trials 8, 68S-73S.

Kaplan, R. C., Ho, G. Y., Xue, X., Rajpathak, S., Cushman, M. Rohan, T. E., Strickler, H. D., Scherer, P. E., and Anastos, K. (2007). Within-individual stability of obesity-related biomarkers among women. Cancer Epidemiol. Biomarkers Prev. 16, 1291-1293.

Kattan, M., Kumar, R., Bloomberg, G. R., Mitchell, H. E., Calatroni, A., Gergen, P. J., Kercsmar, C. M., Visness, C. M., Matsui, E. C., Steinbach, S. F., Szefler, S. J., Sorkness, C. A., Morgan, W. J., Teach, S. J., and Gan, V. N. (2010). Asthma control, adiposity, and adipokines among inner-city adolescents. J. Allergy Clin. Immunol. 125, 584-592.

Kondo, H., Shimomura, I., Matsukawa, Y., Kumada, M., Takahashi, M., Matsuda, M., Ouchi, N., Kihara, S., Kawamoto, T., Sumitsuji, S., Funahashi, T., and Matsuzawa, Y. (2002). Association of adiponectin mutation with type 2 diabetes: a candidate gene for the insulin resistance syndrome. Diabetes 51, 2325-2328. 
Kumada, M., Kihara, S., Ouchi, N., Kobayashi, H., Okamoto, Y., Ohashi, K., Maeda, K., Nagaretani, H., Kishida, K., Maeda, N., Nagasawa, A., Funahashi, T., and Matsuzawa, Y. (2004). Adiponectin specifically increased tissue inhibitor of metalloproteinase-1 through interleukin-10 expression in human macrophages. Circulation 109, 2046-2049.

Lang, J. E., Feng, H., and Lima, J. J. (2009). Body mass indexpercentile and diagnostic accuracy of childhood asthma. J. Asthma 46, 291-299.

Lawlor, D. A., Davey Smith, G., Ebrahim, S., Thompson, C., and Sattar, N. (2005). Plasma adiponectin levels are associated with insulin resistance, but do not predict future risk of coronary heart disease in women. J. Clin. Endocrinol. Metab. 90, 5677-5683.

Lukanova, A., Soderberg, S., Kaaks, R., Jellum, E., and Stattin, P. (2006). Serum adiponectin is not associated with risk of colorectal cancer. Cancer Epidemiol. Biomarkers Prev. 15, 401-402.

Medoff, B. D., Okamoto, Y., Leyton, P., Weng, M., Sandall, B. P., Raher, M. J., Kihara, S., Bloch, K. D., Libby, P., and Luster, A. D. (2009). Adiponectindeficiency increases allergic airway inflammation and pulmonary vascular remodeling. Am. J. Respir. Cell Mol. Biol. 41, 397-406.

Miller, M., Cho, J. Y., Pham, A., Ramsdell, J., and Broide, D. H. (2009). Adiponectin and functional adiponectin receptor 1 are expressed by airway epithelial cells in chronic obstructive pulmonary disease. $J$. Immunol. 182, 684-691.

Miller, M. R., Hankinson, J., Brusasco, V., Burgos, F., Casaburi, R., Coates, A., Crapo, R., Enright, P., Van Der Grinten, C. P. M., Gustafsson, P., Jensen, R., Johnson, D. C., Macintyre, N., Mckay, R., Navajas, D., Pedersen, O. F., Pellegrino, R., Viegi, G., and Wanger, J. (2005). Standardisation of spirometry. Eur. Respir. J. 26, 319-338.

Mosen, D. M., Schatz, M., Magid, D. J., and Camargo, C. A. Jr. (2008). The relationship between obesity and asthma severity and control in adults. J. Allergy Clin. Immunol. 122, 507-511 e506.

Nagel, G., Koenig, W., Rapp, K., Wabitsch, M., Zoellner, I., and Weiland, S. K. (2009). Associations of adipokines with asthma, rhino conjunctivitis, and eczema in German schoolchildren. Pediatr. Allergy Immunol. 20, 81-88.

National Heart Lung and Blood Institute, NaEaPP. (2007a). Expert panel report 3 (EPR-3): guidelines for the diagnosis and management of asthma-summary report 2007. J. Allergy Clin. Immunol. 120, S94S138.

National Heart Lung and Blood Institute, NaEaPP. (2007b). Expert Panel Report 3: Guidelines for the Diagnosis and Management of Asthma. Bethesda, MD: Department of Health and Human Services, National Institutes of Health. [Available at http://www.nhlbi.nih.gov/guidelines/ asthma/asthgdln.pdf]

Okamoto, Y., Kihara, S., Ouchi, N., Nishida, M., Arita, Y., Kumada, M., Ohashi, K., Sakai, N., Shimomura, I., Kobayashi, H., Terasaka, N., Inaba, T., Funahashi, T., and Matsuzawa, Y. (2002). Adiponectin reduces atherosclerosis in apolipoprotein Edeficient mice. Circulation 106, 2767-2770.

Onat, A., Hergenc, G., Dursunoglu, D., Kucukdurmaz, Z., Bulur, S., and Can, G. (2008). Relatively high levels of serum adiponectin in obese women, a potential indicator of antiinflammatory dysfunction: relation to sex hormone-binding globulin. Int. J. Biol. Sci. 4, 208-214.

Ouchi, N., Kihara, S., Arita, Y., Maeda, K., Kuriyama, H., Okamoto, Y., Hotta, K., Nishida, M., Takahashi, M., Nakamura, T., Yamashita, S., Funahashi, T., and Matsuzawa, Y. (1999). Novel modulator for endothelial adhesion molecules: adipocyte-derived plasma protein adiponectin. Circulation 100, 2473-2476.

Page, S. T., Herbst, K. L., Amory, J. K., Coviello, A. D., Anawalt, B. D., Matsumoto, A. M., and Bremner, W. J. (2005). Testosterone administration suppresses adiponectin levels in men. J. Androl. 26, 85-92.

Pischon, T., Hotamisligil, G. S., and Rimm, E. B. (2003). Adiponectin: stability in plasma over 36 hours and within-person variation over 1 year. Clin. Chem. 49, 650-652.

Reddel, H. K., Taylor, D. R., Bateman, E. D., Boulet, L. P., Boushey, H. A., Busse, W. W., Casale, T. B., Chanez, P., Enright, P. L., Gibson, P. G., De Jongste, J. C., Kerstjens, H. A., Lazarus, S. C., Levy, M. L., O'byrne, P. M., Partridge, M. R., Pavord, I. D., Sears, M. R., Sterk, P. J., Stoloff, S. W., Sullivan, S. D., Szefler, S. J., Thomas, M. D., and Wenzel, S. E. (2009). An official American Thoracic Society/European Respiratory Society statement: asthma control and exacerbations: standardizing endpoints for clinical asthma trials and clinical practice. Am. J. Respir. Crit. Care Med. 180, 59-99.
Shin, J. H., Kim, J. H., Lee, W. Y., and Shim, J. Y. (2008). The expression of adiponectin receptors and the effects of adiponectin and leptin on airway smooth muscle cells. Yonsei Med. J. $49,804-810$.

Shore, S. A. (2006). Obesity and asthma: cause for concern. Curr. Opin. Pharmacol. 6, 230-236.

Shore, S. A., Terry, R. D., Flynt, L., Xu, A., and Hug, C. (2006). Adiponectin attenuates allergen-induced airway inflammation and hyperresponsiveness in mice. J. Allergy Clin. Immunol. 118, 389-395.

Sood, A., Camargo, Jr. C. A., and Ford, E. S. (2006). Association between leptin and asthma in adults. Thorax 61 , 300-305.

Sood, A., Cui, X., Qualls, C., Beckett, W. S., Gross, M. D., Steffes, M. W., Smith, L. J., and Jacobs, D. R. Jr. (2008). Association between asthma and serum adiponectin concentration in women. Thorax 63 , 877-882.

Sood, A., Qualls, C., Seagrave, J., Stidley, C., Archibeque, T., Berwick, M., and Schuyler, M. (2009). Effect of specific allergen inhalation on serum adiponectin in human asthma. Chest $135,287-294$.

Summer, R., Little, F. F., Ouchi, N., Takemura, Y., Aprahamian, T., Dwyer D., Fitzsimmons, K., Suki, B., Parameswaran, H., Fine, A., and Walsh, K. (2008). Alveolar macrophage activation and an emphysema-like phenotype in adiponectin-deficient mice. Am. J. Physiol. Lung Cell Mol. Physiol. 294, L1035-L1042.

Sutherland, E. R., Lehman, E. B., Teodorescu, M., and Wechsler, M. E. (2009a). Body mass index and phenotype in subjects with mildto-moderate persistent asthma. J. Allergy Clin. Immunol. 123, 1328-1334 e1321.

Sutherland, T. J., Sears, M. R., Mclachlan, C. R., Poulton, R., and Hancox, R. J. (2009b). Leptin, adiponectin, and asthma: findings from a population-based cohort study. Ann. Allergy Asthma Immunol. 103, 101-107.

Tantisira, K. G., Litonjua, A. A., Weiss, S. T., and Fuhlbrigge, A. L. (2003). Association of body mass with pulmonary function in the childhood asthma management program (CAMP). Thorax 58, 1036-1041.

Taylor, B., Mannino, D., Brown, C., Crocker, D., Twum-Baah, N., and Holguin, F. (2008). Body mass index and asthma severity in the National Asthma Survey. Thorax 63, 14-20.

The Enfumosa Study Group. (2003). The ENFUMOSA cross-sectional European multicentre study of the clinical phenotype of chronic severe asthma. European network for understanding mechanisms of severe asthma. Eur. Respir. J. 22, 470-477.

Ungar, W. J., Chapman, K. R., and Santos, M. T. (2002). Assessment of a medication-based asthma index for population research. Am. J. Respir. Crit. Care Med. 165, 190-194.

Vortmann, M., and Eisner, M. D. (2008). BMI and health status among adults with asthma. Obesity (Silver Spring) $16,146-152$.

Wenzel, S. E., and Busse, W. W. (2007). Severe asthma: lessons from the severe asthma research program. $J$. Allergy Clin. Immunol. 119, 14-21; quiz 22-13.

Wulster-Radcliffe, M. C., Ajuwon, K. M., Wang, J., Christian, J. A., and Spurlock, M. E. (2004). Adiponectin differentially regulates cytokines in porcine macrophages. Biochem. Biophys. Res. Commun. 316 924-929.

Zhu, M., Hug, C., Kasahara, D. I., Johnston, R. A., Williams, A. S., Verbout, N. G., Si, H., Jastrab, J., Srivastava, A., Williams, E. S., Ranscht, B., and Shore, S. A. (2010). Impact of adiponectin deficiency on pulmonary responses to acute ozone exposure in mice. Am. J. Respir. Cell Mol. Biol. 43, 487-497.

Conflict of Interest Statement: Authors have no relationships financial, commercial or otherwise that might be perceived by the academic community as representing a potential conflict of interest. The research was conducted in the absence of any commercial or financial relationships that could be construed as a potential conflict of interest.

Received: 08 August 2011; paper pending published: 22 August 2011; accepted: 12 September 2011; published online: 05 October 2011.

Citation: Sood A, Dominic E, Qualls C, Steffes MW, Thyagarajan B, Smith LJ, Lewis CE and Jacobs DR Jr (2011) Serum adiponectin is associated with adverse outcomes of asthma in men but not in women. Front. Pharmacol. 2:55. doi: 10.3389/fphar.2011.00055

This article was submitted to Frontiers in Respiratory Pharmacology, a specialty of Frontiers in Pharmacology.

Copyright (c) 2011 Sood, Dominic, Qualls, Steffes, Thyagarajan, Smith, Lewis and Jacobs Jr. This is an open-access article subject to a non-exclusive license between the authors and Frontiers Media $S A$, which permits use, distribution and reproduction in other forums, provided the original authors and source are credited and other Frontiers conditions are complied with. 